\title{
Sensory and motor neuronopathy in a patient with the A382P TDP-43 mutation
}

\author{
Jean-Philippe Camdessanché ${ }^{1,2}$, Véronique V Belzil ${ }^{3}$, Guillemette Jousserand ${ }^{1}$, Guy A Rouleau ${ }^{3,4,5}$, \\ Christelle Créac' $h^{1}$, Philippe Convers ${ }^{1}$, Jean-Christophe Antoine ${ }^{1,2^{*}}$
}

\begin{abstract}
Patients with TARDBP mutations have so far been classified as ALS, sometimes with frontal lobe dysfunction. A 66year-old patient progressively developed a severe sensory disorder, followed by a motor disorder, which evolved over nine years. Symptoms started in the left hand and slowly involved the four limbs. Investigations were consistent with a mixed sensory and motor neuronopathy. A heterozygous change from an alanine to a proline at amino acid 382 was identified in exon 6 of the TARDPB gene (p.A382P). This case expands the phenotypic spectrum associated with mutations in the TARDBP gene and shows that sensory neurons can be severely damaged early in the course of the disease, following a propagating process, with an orderly progression from a focal starting point. A combination of severe sensory and motor neuronopathy is rarely encountered in clinical practice. The possibility of an A382P TDP-43 mutation should be considered in patients with such an association.
\end{abstract}

\section{Background}

TDP-43, a protein involved in RNA processing, is thought to play a determinant role in the pathophysiology of amyotrophic lateral sclerosis (ALS), in which it is abnormally processed and sequestered in the cytoplasm, the perikaryon, and dystrophic neurites of neurons [1,2]. Variations in the TARDPB gene, which encodes TDP43 , occur in about $3 \%$ of sporadic and familial cases of ALS [3] and are mostly found in cases with a usually predominant lower motor neuron involvement and in a few patients with cognitive deficits [4-6]. We here report the case of a patient with the A382P TDP-43 mutation who developed a unique phenotype consisting of a slowly spreading sensory and motor neuronopathy.

\section{Case presentation}

A 72-year-old right-handed non-smoker man was referred in March 2001 after a 6-year progression of a sensory, then motor, deficit in the left arm. He reported that his mother died when she was 56 after a 4-year evolution of a neurological disease that started in the upper limbs and progressively paralyzed her, including speech and deglutition. Symptoms first appeared in the

\footnotetext{
* Correspondence: j.christophe.antoine@chu-st-etienne.fr

${ }^{1}$ Service de Neurologie, CHU de Saint-Etienne, Saint-Etienne, France

Full list of author information is available at the end of the article
}

patient in April 1995, with paresthesia in the left hand (month 1 = M1). In July (M4), motor deficit and muscle atrophy were absent, but $128 \mathrm{~Hz}$ tuning fork perception was reduced in the left index finger. Motor conduction velocities $(\mathrm{MCV})$ and compound motor action potentials (CMAP) were normal in both the median and ulnar nerve, while sensory action potentials (SAP) were reduced in the left median and ulnar nerves and slightly reduced in the right sural nerve (see Additional file 1 for the electrophysiological methods and the detailed results of the ENMG study). Needle examination showed only an increased number of polyphasic motor unit potentials (MUPs) in the left abductor pollicis brevis (28\% of MUPs). The cervical spine and plexus MRI was normal. Because of persistent paresthesia, somatosensory evoked potentials (SEPs) were recorded in October 1996 (M18) and were normal in the right median nerve, whereas the left N9 potential amplitude was reduced and the N13, P14, and N30 potentials abolished (Table 1).

Four years later, in January 1998 (M35), motor deficit and muscle atrophy appeared in the left arm, while the sensory symptoms extended to the elbow. In July (M40), SAPs were reduced in both the median and ulnar nerve, predominantly on the left. MCVs and CMAPs were normal. Needle examination showed chronic neurogenic changes in the abductor policis brevis, abductor digiti
C Biomed Central

๑ 2011 Camdessanché et al; licensee BioMed Central Ltd. This is an Open Access article distributed under the terms of the Creative Commons Attribution License (http://creativecommons.org/licenses/by/2.0), which permits unrestricted use, distribution, and reproduction in any medium, provided the original work is properly cited. 
Table 1 Evolution of sensory evoked potentials (SEPs) and sensory action potentials (SAPs) with disease course

\begin{tabular}{ccccccccc}
\hline \multicolumn{1}{c}{ RIGHT } & \multicolumn{7}{c}{ LEFT } \\
\hline Months & $\mathbf{4 - 1 8}$ & $\mathbf{4 0}$ & $\mathbf{6 8 - 7 2}$ & $\mathbf{1 0 4}$ & $\mathbf{4 - 1 8}$ & $\mathbf{4 0}$ & $\mathbf{6 8 - 7 2}$ & $\mathbf{1 0 4}$ \\
\hline Median nerve & & & & & & & & \\
SEPS & & & & & & & & \\
N9 & + & + & & - & + & - & & - \\
N13 & + & - & ND & - & - & - & ND & - \\
P14 & + & + & & - & - & - & & - \\
N20 & + & + & & + & - & - & & - \\
SAP $(\mu \mathrm{V})$ N $>8 \mu \mathrm{VV}$ & 13.8 & 12.7 & 4.75 & 0 & 6.8 & 5 & 0 & 0 \\
\hline Tibial nerve & & & & & & & & \\
SEPs & & & & & & & & \\
N20 & ND & ND & - & - & ND & ND & - & - \\
P30 & & & - & - & & & - & -
\end{tabular}

Sural nerve

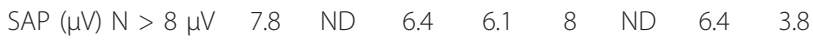

SEPs were recorded after stimulation of the median nerve at the wrist or the tibial nerve at the ankle, and SAPs were recorded in the median or sural nerves. N9, Erb point; N13, cervical spinal cord posterior horn; P14, gracilis and cuneatus nuclei; N20, parietal cortex, and P30, frontal cortex. ' + ' indicates a recorded potential and '-'an absent potential. ND: not done. SAPs were dromically registered with surface electrode in the ulnar nerve (head level, normal $\geq 8 \mu \mathrm{V}$ ) and antidromically in the sural nerve (foot level, normal $\geq 8 \mu \mathrm{V})$.

minimi, first dorsal interosseus, and extensor carpi radialis longus in both hands, but predominantly on the left side.

In November 2000 (M68), the left arm showed diffuse muscular atrophy. Tendon reflexes were abolished and fasciculations were observed in the left biceps brachii and pectoralis major. In March 2001 (M72), the motor deficit was restricted to the left arm, with an MRC score of 3 in the deltoideus, biceps brachii, triceps brachii, and abductor pollicis brevis muscles. Muscle atrophy was restricted to the left upper limb and fasciculations were observed in all four limbs. Tendon reflexes were absent in the left arm and normal in the other limbs. The plantar response was indifferent on both sides. Bulbar involvement was absent. Tuning fork $128 \mathrm{~Hz}$ perception was absent at the left wrist and elbow, present at the clavicle, and reduced at the left ankle and knee. Stereognosia and graphesthesia were abolished in the left hand, while pain and thermal sensation were almost normal. There was no cognitive impairment and no dysautonomic manifestation. SAPs were absent in the left radial, ulnar, and median nerves and reduced in the other limbs. CMAPs were reduced in the left median and ulnar nerves and normal on the right side and in both peroneal and tibial nerves. Motor conduction velocities and F-wave latencies were normal. Fibrillation potentials were recorded in the upper limbs and fasciculations were present in the left vastus lateralis. SEPs were not recordable in the left median and both tibial nerves, but were normal in the right median nerve with the exception of a reduced N9 potential (Table 1).

The motor deficit slowly progressed in the left arm and, in January 2004 (M104), proximal weakness appeared in the left leg. The Norris limb score was 45/ 63 and the bulbar score 42/42. Forced vital capacity was normal. SAPs could not be recorded in the upper limbs and were severely reduced in the lower limbs, especially on the left side. CMAPs were reduced or absent in the left median, ulnar, tibial, and peroneal nerves and reduced in the right median and peroneal nerves. Conduction velocities were normal. Positive sharp waves and fibrillation potentials were recorded in all four limbs. SEPs were abolished in the four limbs, except in the right median nerve, where a N20 potential was recorded (Table 1). CO2 laser-evoked potentials (LEPs), evaluating $\mathrm{A} \delta$ and $\mathrm{C}$ fibers, were abolished in both hands and feet. The patient died suddenly in June 2004 (M110). No autopsy was performed. The clinical and neurophysiological data are summarized in Figure 1.

The following investigations were performed in October 2001 (M79) and were normal: cerebrospinal fluid analysis, blood cell count, ionogram, serum creatinine, glycemia, liver enzymes, vitamin E, B12 and folates, TSH, hexosaminidase A and B, amino acid chromatography, and Apo A and Apo B. Serology was negative for HIV, VDRL-TPHA, and hepatitis B and C. Screening for monoclonal gammopathy, red blood cell acanthocytosis, and antinuclear, anti-SSA, anti-SSB, anti-mitochondrial, anti-gliadin, anti-disialosyl ganglioside, and antionconeural antibodies, including $\mathrm{Hu}$ and CRMP5/CV2 antibodies, was negative. The salivary gland biopsy was normal. No mutations of the frataxin and TTR genes were found. X-ray and CT thoracic scans were normal, as was abdominal ultrasound. A muscle biopsy (left vastus lateralis) showed neurogenic changes without mitochondrial abnormalities.

In December 2001 (M81), a left superficial radial nerve biopsy was normal on paraffin-embedded H-S and Congo red-stained sections. Semithin sections disclosed a severe reduction in large myelinated fiber density (Figure 2A and 2B). Only a few fibers were degenerating. Regenerating clusters were absent. Immunohistochemistry was performed on formalin-fixed paraffin-embedded samples of the nerve biopsy from the patient and, as control, a patient with a sensory neuropathy using rabbit polyclonal anti-human TDP43 antibodies (Protein Tech Group, Inc; Chicago, IL, USA) at a 1/1000 dilution. Nerve sections were deparaffinised, subjected to immunochemical detection with the antibodies, processed with a ultraView Universal DAB Detection Kit (Ventana Medical Systems, S.A., Illkirch, France), and counterstained with H-E. In both the patient and control, Schwann cell 


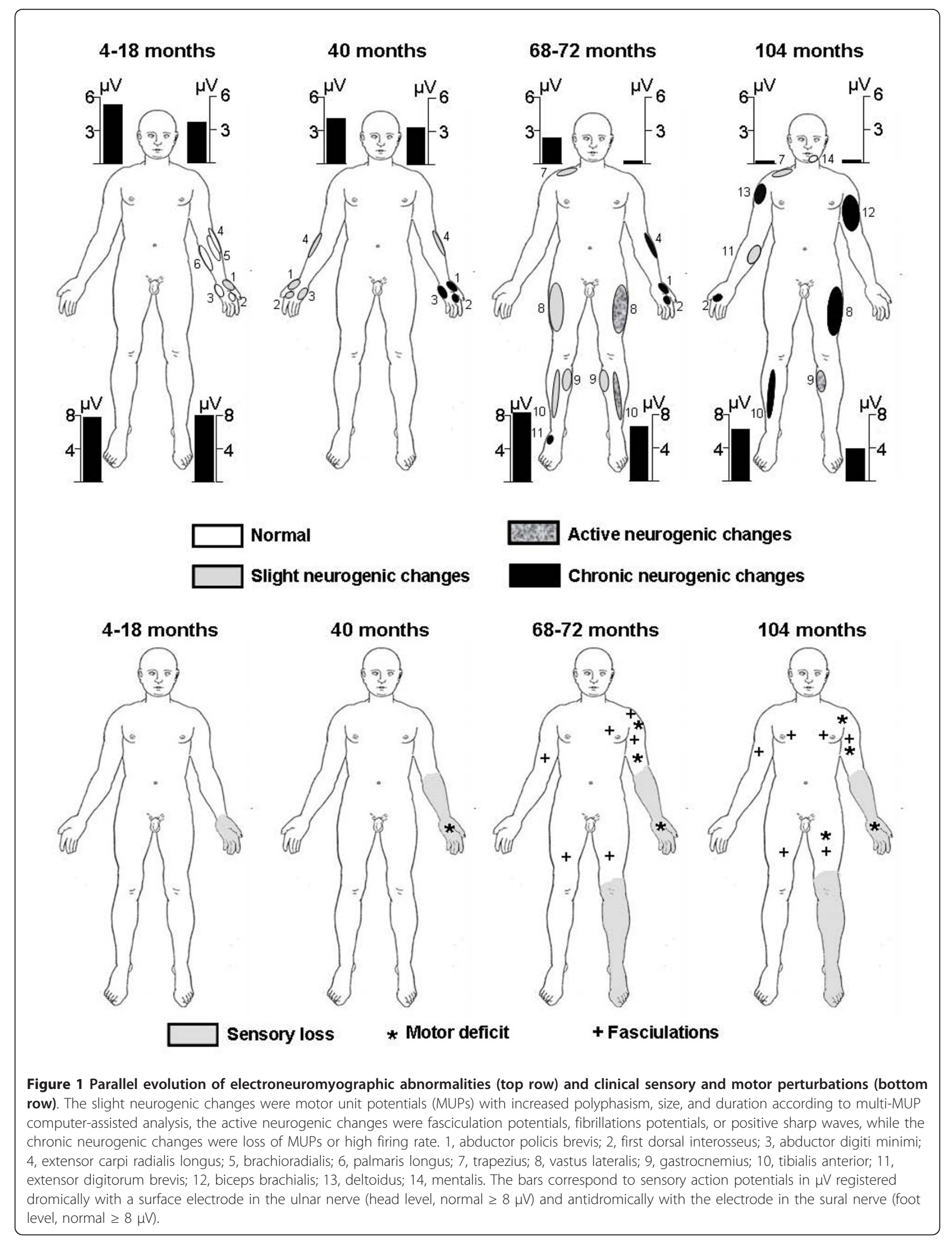



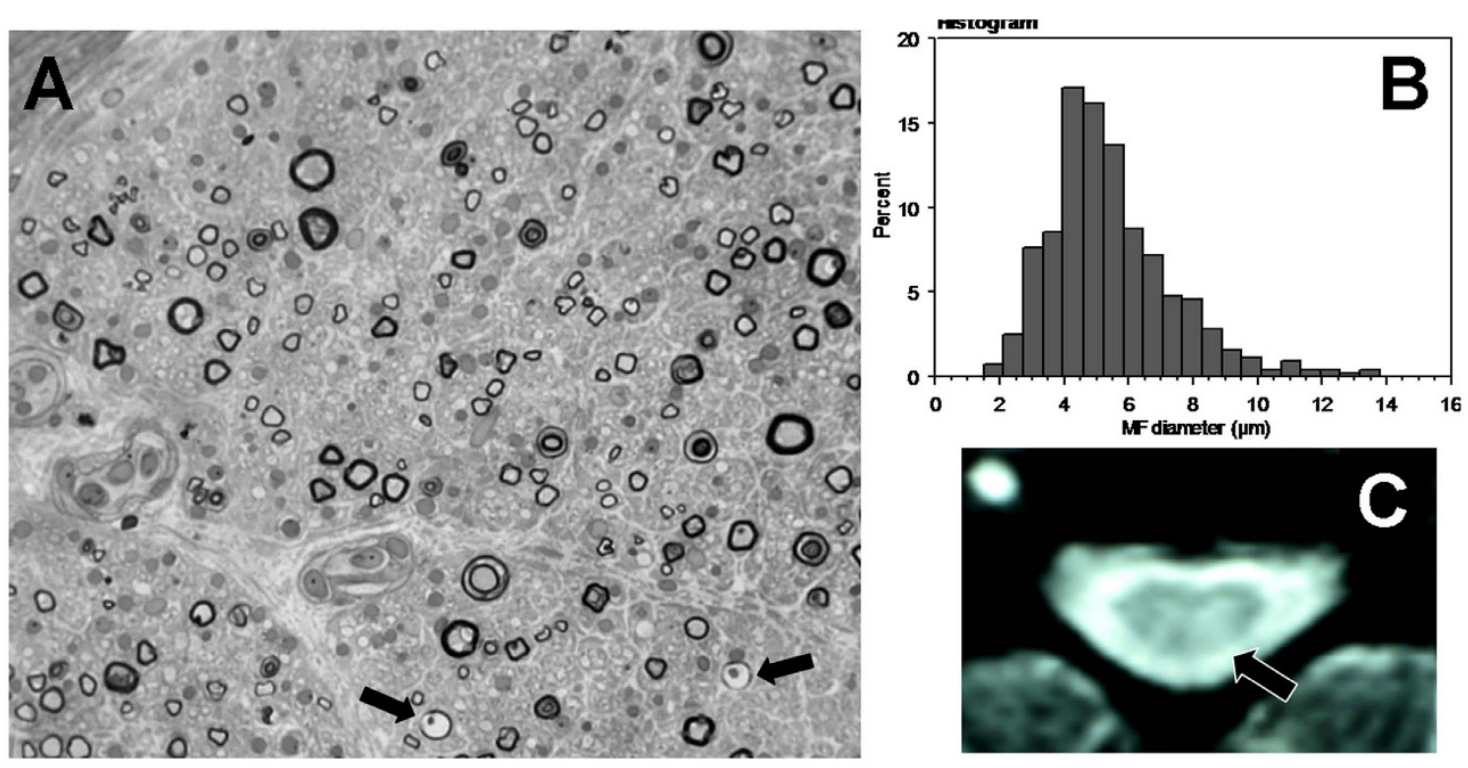

Figure 2 Fiber loss mainly involved large fibers with a few degenerating axons (arrows) and no regenerating cluster as seen in the photograph of the superficial radial nerve biopsy (semithin section $\times 40$ ) in (A) and the histogram in (B), (C), Abnormal hyperintensity in the left posterior column on the cervical spinal cord T2-MRI.

nuclei were immunolabeled, while no labeling was observed in the cytoplasm or in axons (Figure 3). In June 2003, the brain MRI was normal, while the T2 weighted cervical spine MRI showed a hypersignal in the left posterior column (Figure 2C).

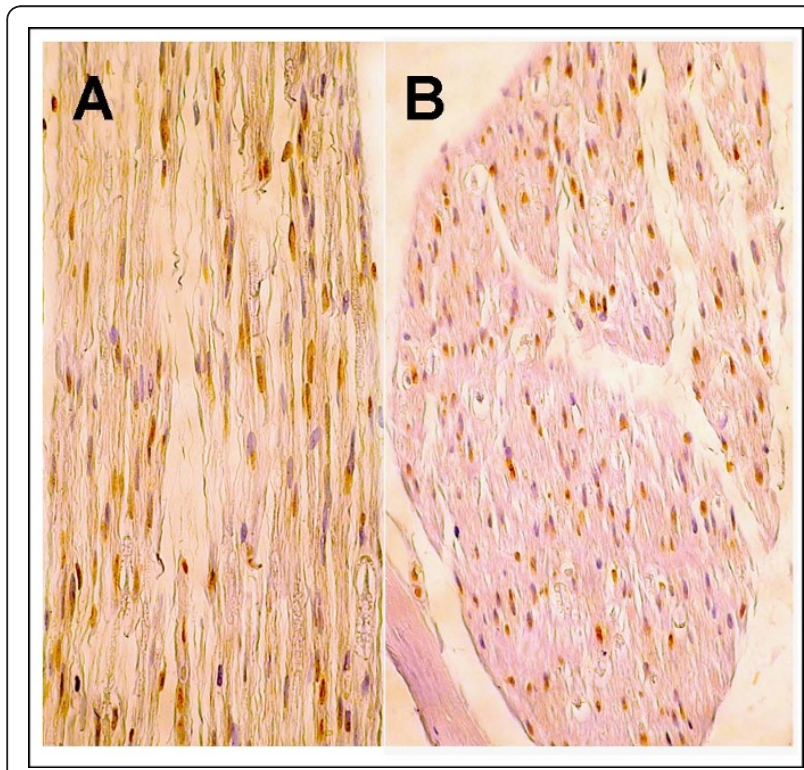

Figure 3 Immunohistochemical study using anti-TDP-43 antibodies of the patient's nerve biopsy $(A \times 40)$ and a control nerve biopsy $(\mathbf{B} \times \mathbf{3 0})$. In both nerves, only Schwann cell nuclei are immunolabeled.

\section{Genetic analysis}

The sample was sequenced for mutations in the SOD1, $T A R D B P$, and FUS genes. A previously reported heterozygous change from an alanine to a proline at amino acid 382 [7], resulting from the substitution of a guanine by a cytosine at position one of the codon (c.1278G > C), was identified in exon 6 of the TARDPB gene (p.A382P) (Figure 4). This variant was not identified in 360 control participants [8]. Family members were not available for genetic analysis. The mutated alanine is conserved in seven out of nine tested species, but is a proline in the mouse and rat (Figure 4B). Two bioinformatics programs, Polyphen [9] and SIFT [10], were used to predict the effect of the polymorphism on the protein. Polyphen predicted the change to be benign, while SIFT predicted that it would affect protein function, with a low confidence in the prediction.

\section{Discussion}

This is the first time, to our knowledge, that a variant in TARDBP has been identified in a patient with a sensory and motor phenotype. It is very unlikely that this resulted from a coincidental association of sensory neuropathy and motor neuron disease, since the motor and sensory manifestations started in the same metameric territory and followed a parallel course. Moreover, an extensive work-up found no other cause of sensory neuropathy. Despite the absence of pathological evidence, the severe sensory involvement is very suggestive of 
A

Wild type

Heterozygous patient with A382P missense mutation
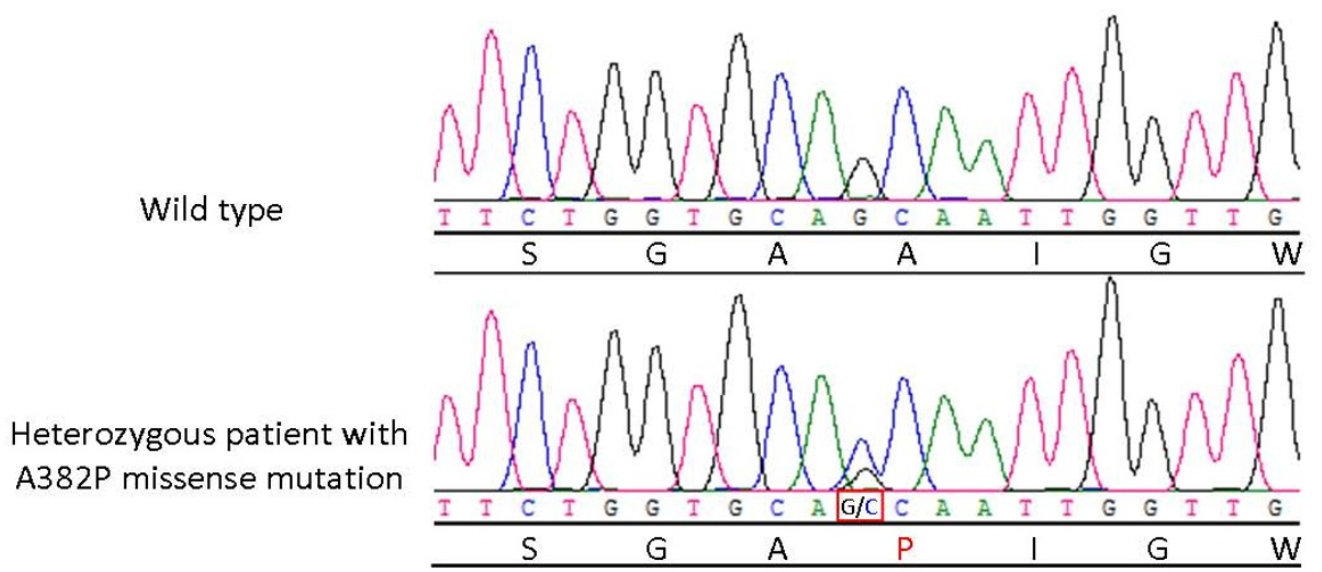

B

$\begin{array}{ccc}\text { S N S G A A I G W G S A S N A G S G S - G F N G G F G S S M Majority } \\ 380 & 390 & 400\end{array}$

SN S G A A I G W S A S N G S G - G F N G G F G S S M SN S G A A I GW G A A N A G G S- G F N G G G S M S N S G A A I G W G S A N A G S G S - G F N G G F S S M SN S G A A I G W G S A N A G S S - G F N G G F S S M S N S G A D L G W G A S N A G G S - G F N G F G S S M S N S G A $\underline{\text { p }}$ L G W G S A S N A S G S - G F N G G F G S S M

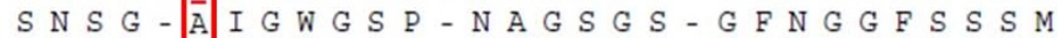
$S N S G-A I G W G S P-N A G S G S-G F N G G$ F S S $M$ S S S A - A L G W G T G N S G A A S A F N S S G S S M

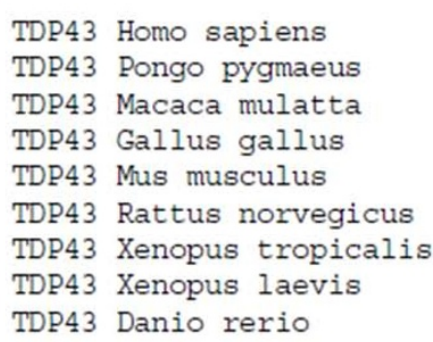

TDP43 Homo sapiens TDP43 Pongo pygmaeus TDP43 Macaca mulatta TDP43 Gallus gallus TDP43 Mus musculus TDP4 3 Rattus norvegicus Xenopus tropicalis TDP43 Danio rerio

Figure 4 Sequence traces and across-species conservation. (A) Sequence trace for the p.A382P variant; the patient is shown below the wild type sequence. The red square marks the substituted nucleotide and the substituted amino acid is in red. (B) Conservation across nine species of amino acids 377 to 405 of TDP-43 is shown using the Clustal W method. Amino acid 382 is boxed in red and the proline present in the mouse and rat is underlined in red.

sensory neuronopathy, i.e. of sensory neuron degeneration in dorsal root ganglia [11]. Thus, the sensory perturbations had a typical non-length-dependent pattern both clinically and on sensory nerve conduction study. The presence of SEPs with early absent N13 potentials and still recordable N9 potentials also suggests sensory neuronopathy [12]. Moreover, this indicates that the central process of the sensory neurons was involved before the peripheral process. Central process degeneration was also demonstrated by the presence of abnormal signals in the posterior column on spinal cord MRI, as reported previously [13]. Finally, the CO2 laser-evoked potentials indicated that, despite a predominant large neuron involvement, small nociceptive neurons were also involved.

The patient's mother's history was highly suggestive of neuromuscular disease, arguing for a hereditary transmission of the disorder. The A382P mutation identified in the patient has been reported in another ALS case, but the sensory phenotype of this patient was not specified in the publication [7]. The mutation, which was absent in 720 control chromosomes [8], was predicted to have mixed effects by two different bioinformatics software programs. The missense mutation, which is also a proline in the rat and mouse, was located in the C-terminal glycine-rich region, where most TARDPB mutations have been found [14]. Thus, with the available information, it can be hypothesized that the $T A R D P B$ variant actually caused the particular phenotype of this patient.

Sensory neuron involvement had not previously been reported for TDP-43 mutations and, when mentioned, SAPs have been reported as normal $[15,16]$. Pathological studies in the few available cases $[4,17]$ and in transgenic models $[18,19]$ did not specifically examine dorsal root ganglia, although TDP-43 is normally expressed in 
sensory neuron nuclei [20]. On the patient's nerve biopsy, no abnormal accumulation of TDP-43 was found in peripheral axons, in keeping with the fact that, in the central nervous system of patients with TARDBP mutations or sporadic ALS, the protein does not accumulate in axons, but in the neuron cell body and dendrites [1,4].

ALS is usually considered as a propagating process that recruits locally and spreads with an orderly progression [21]. In this patient, the electrophysiological results suggested a pre-existing widespread sensory dysfunction upon which the degenerative process developed focally in the left arm, then extended to the contralateral side and, through descending pathways, to the lumbar region. At each level, sensory neurons were electrophysiologically involved before motor neurons.

The combination of severe sensory and motor neuronopathy is rarely encountered in clinical practice. It has been reported in patients with paraneoplastic Hu-antibodies, [22] in facial onset sensory and motor neuronopathy (FOSMN) [23], and in rare genetic diseases, such as Tangier disease [24]. The A382P TDP-43 mutation should be considered in patients with such an association.

\section{Conclusions}

This case broadens the spectrum of neurological syndromes associated with TARDBP mutations. It shows that, in rare circumstances, sensory neurons can be involved early and as severely as motor neurons and provides arguments in favor of the hypothesis that the disease followed a propagating process, with a spreading and orderly progression from a focal starting point.

\section{Consent}

The patient gave informed consent for the genetic analysis. A copy of the written consent is available for review by the Editor-in-Chief of this journal. Consent for publication could not be obtained from the family of the deceased patient, as they could not be reached.

\section{Additional material}

Additional file 1: Sensory and motor neuronopathy in a patient with the A382P TDP-43 mutation. This file contains the detailed

electrophysiological methods used for this study and the complete results of the ENMG study.

\begin{abstract}
Acknowledgements
The authors express their grateful thanks to Dr Thierry Maisonobe for providing the anti-TDP-43 antibodies and to Dr Michel Peoc'h for performing the immunohistological analysis.
\end{abstract}

\section{Author details}

'Service de Neurologie, CHU de Saint-Etienne, Saint-Etienne, France.

${ }^{2}$ Université de Lyon, F-42023, Saint-Etienne, France. ${ }^{3}$ Centre of Excellence in
Neuromics of Université de Montréal, CHUM Research Center, Montreal, Quebec, H2L 4M1, Canada. ${ }^{4}$ Université de Montreal, Faculty of Medicine, Department of Medicine, Montreal, Quebec, H3C 3J7, Canada. ${ }^{5}$ Research Center, CHU Sainte-Justine, Université de Montreal, Montreal, Quebec, H3T 1C5, Canada.

\section{Authors' contributions}

JPC and GJ performed the electroneuromyographical investigations. PC performed the somatosensory evoked potential analysis. CC was responsible for the CO2 laser potential study. JCA performed the pathological study. WB and GAR carried out the molecular genetic studies. JPC and JCA conceived the study, and WB participated in its coordination and helped to draft the manuscript. All authors read and approved the final manuscript.

\section{Competing interests}

The authors declare that they have no competing interests.

Received: 11 October 2010 Accepted: 5 February 2011

Published: 5 February 2011

\section{References}

1. Pamphlett R, Luquin N, Mclean C, Jew SK, Adams L: TDP-43 neuropathology is similar in sporadic amyotrophic lateral sclerosis with or without TDP-43 mutations. Neuropathol Appl Neurobiol 2009, 35:222-5.

2. Geser F, Brandmeir NJ, Kwong LK, Martinez-Lage M, Elman L, Mccluskey L, Xie SX, Lee VM, Trojanowski JQ: Evidence of multisystem disorder in whole-brain map of pathological TDP-43 in amyotrophic lateral sclerosis. Arch Neurol 2008, 65:636-41.

3. Sreedharan J, Blair IP, Tripathi VB, Hu X, Vance C, Rogelj B, Ackerley S, Durnall JC, Williams KL, Buratti E, Baralle F, De Belleroche J, Mitchell JD, Leigh PN, Al-Chalabi A, Miller CC, Nicholson G, Shaw CE: TDP-43 mutations in familial and sporadic amyotrophic lateral sclerosis. Science 2008, 319:1668-72.

4. Van Deerlin VM, Leverenz JB, Bekris LM, Bird TD, Yuan W, Elman LB, Clay D, Wood EM, Chen-Plotkin aS, Martinez-Lage M, Steinbart E, Mccluskey L, Grossman M, Neumann M, Wu IL, Yang WS, Kalb R, Galasko DR, Montine TJ, Trojanowski JQ, Lee VM, Schellenberg GD, Yu CE: TARDBP mutations in amyotrophic lateral sclerosis with TDP-43 neuropathology: a genetic and histopathological analysis. Lancet Neurol 2008, 7:409-16.

5. Corrado L, Ratti A, Gellera C, Buratti E, Castellotti B, Carlomagno Y, Ticozzi N, Mazzini L, Testa L, Taroni F, Baralle FE, Silani V, D'alfonso S: High frequency of TARDBP gene mutations in Italian patients with amyotrophic lateral sclerosis. Hum Mutat 2009, 30:688-94.

6. Borroni B, Bonvicini C, Alberici A, Buratti E, Agosti C, Archetti S, Papetti A, Stuani C, Di Luca M, Gennarelli M, Padovani A: Mutation within TARDBP leads to frontotemporal dementia without motor neuron disease. Hum Mutat 2009, 30:E974-83.

7. Daoud H, Valdmanis PN, Kabashi E, Dion P, Dupre N, Camu W, Meininger V, Rouleau GA: Contribution of TARDBP mutations to sporadic amyotrophic lateral sclerosis. J Med Genet 2009, 46:112-4.

8. Kabashi E, Valdmanis PN, Dion P, Spiegelman D, Mcconkey BJ, Vande Velde C, Bouchard JP, Lacomblez L, Pochigaeva K, Salachas F, Pradat PF, Camu W, Meininger V, Dupre N, Rouleau GA: TARDBP mutations in individuals with sporadic and familial amyotrophic lateral sclerosis. Nat Genet 2008, 40:572-4.

9. Adzhubei IA, Schmidt S, Peshkin L, Ramensky VE, Gerasimova A, Bork P, Kondrashov aS, Sunyaev SR: A method and server for predicting damaging missense mutations. Nat Methods 7:248-9.

10. Ng PC, Henikoff S: Predicting deleterious amino acid substitutions. Genome Res 2001, 11:863-74.

11. Camdessanche JP, Jousserand G, Ferraud K, Vial C, Petiot P, Honnorat J, Antoine JC: The pattern and diagnostic criteria of sensory neuronopathy: a case-control study. Brain 2009, 132:1723-33.

12. Lauria G, Pareyson D, Sghirlanzoni A: Neurophysiological diagnosis of acquired sensory ganglionopathies. Eur Neurol 2003, 50:146-52.

13. Lauria G, Pareyson D, Grisoli M, Sghirlanzoni A: Clinical and magnetic resonance imaging findings in chronic sensory ganglionopathies. Ann Neurol 2000, 47:104-9.

14. Lagier-Tourenne C, Cleveland DW: Rethinking ALS: the FUS about TDP-43. Cell 2009, 136:1001-4. 
15. Kuhnlein P, Sperfeld aD, Vanmassenhove B, Van Deerlin V, Lee VM, Trojanowski JQ, Kretzschmar HA, Ludolph aC, Neumann M: Two German kindreds with familial amyotrophic lateral sclerosis due to TARDBP mutations. Arch Neurol 2008, 65:1185-9.

16. Gitcho MA, Bigio EH, Mishra M, Johnson N, Weintraub S, Mesulam M, Rademakers R, Chakraverty S, Cruchaga C, Morris JC, Goate aM, Cairns NJ: TARDBP 3 '-UTR variant in autopsy-confirmed frontotemporal lobar degeneration with TDP-43 proteinopathy. Acta Neuropathol 2009, 118:633-45.

17. Neumann M, Kwong LK, Lee EB, Kremmer E, Flatley A, Xu Y, Forman MS, Troost D, Kretzschmar HA, Trojanowski JQ, Lee VM: Phosphorylation of S409/410 of TDP-43 is a consistent feature in all sporadic and familial forms of TDP-43 proteinopathies. Acta Neuropathol 2009, 117:137-49.

18. Zhou H, Huang C, Chen H, Wang D, Landel CP, Xia PY, Bowser R, Liu YJ, Xia XG: transgenic rat model of neurodegeneration caused by mutation in the TDP gene. PLoS Genet 6:e1000887.

19. Wils H, Kleinberger G, Janssens J, Pereson S, Joris G, Cuijt I, Smits V, Ceuterick-De Groote C, Van Broeckhoven C, Kumar-Singh S: TDP-43 transgenic mice develop spastic paralysis and neuronal inclusions characteristic of ALS and frontotemporal lobar degeneration. Proc Natl Acad Sci USA 107:3858-63.

20. Casafont I, Bengoechea R, Tapia O, Berciano MT, Lafarga M: TDP-43 localizes in mRNA transcription and processing sites in mammalian neurons. J Struct Biol 2009, 167:235-41.

21. Ravits JM, La Spada AR: ALS motor phenotype heterogeneity, focality, and spread: deconstructing motor neuron degeneration. Neurology 2009, 73:805-11.

22. Graus F, Keime-Guibert F, Rene R, Benyahia B, Ribalta T, Ascaso C, Escaramis G, Delattre JY: Anti-Hu-associated paraneoplastic encephalomyelitis: analysis of 200 patients. Brain 2001, 124:1138-48.

23. Vucic S, Tian D, Chong PS, Cudkowicz ME, Hedley-Whyte ET, Cros D: Facial onset sensory and motor neuronopathy (FOSMN syndrome): a novel syndrome in neurology. Brain 2006, 129:3384-90.

24. Antoine JC, Tommasi M, Boucheron S, Convers P, Laurent B, Michel D: Pathology of roots, spinal cord and brainstem in syringomyelia-like syndrome of Tangier disease. J Neurol Sci 1991, 106:179-85.

doi:10.1186/1750-1172-6-4

Cite this article as: Camdessanché et al: Sensory and motor neuronopathy in a patient with the A382P TDP-43 mutation. Orphanet Journal of Rare Diseases 2011 6:4.

\section{Submit your next manuscript to BioMed Central and take full advantage of:}

- Convenient online submission

- Thorough peer review

- No space constraints or color figure charges

- Immediate publication on acceptance

- Inclusion in PubMed, CAS, Scopus and Google Scholar

- Research which is freely available for redistribution

Submit your manuscript at www.biomedcentral.com/submit 